\title{
Nanodiamonds act as Trojan horse for intracellular delivery of metal ions to trigger cytotoxicity
}

Ying Zhu ${ }^{1 *+}$, Yu Zhang ${ }^{1,2+}$, Guosheng Shi ${ }^{3 \dagger}$, Jinrong Yang ${ }^{2,3}$, Jichao Zhang ${ }^{1}$, Wenxin Li ${ }^{1}$, Aiguo Li ${ }^{4}$, Renzhong Tai ${ }^{4}$, Haiping Fang ${ }^{3}$, Chunhai Fan ${ }^{1,5}$ and Qing Huang ${ }^{1 \wedge}$

\begin{abstract}
Background: Nanomaterials hold great promise for applications in the delivery of various molecules with poor cell penetration, yet its potential for delivery of metal ions is rarely considered. Particularly, there is limited insight about the cytotoxicity triggered by nanoparticle-ion interactions. Oxidative stress is one of the major toxicological mechanisms for nanomaterials, and we propose that it may also contribute to nanoparticle-ion complexes induced cytotoxicity.

Methods: To explore the potential of nanodiamonds (NDs) as vehicles for metal ion delivery, we used a broad range of experimental techniques that aimed at getting a comprehensive assessment of cell responses after exposure of NDs, metal ions, or ND-ion mixture: 3-(4,5-dimethylthiazol-2-yl)-2,5-diphenyltetrazolium bromide (MTT) assay, Trypan blue exclusion text, optical microscope observation, synchrotron-based scanning transmission X-ray microscopy (STXM) and micro X-ray fluorescence ( $\mu \mathrm{XRF}$ ) microscopy, inductively coupled plasma-mass spectrometry (ICP-MS), reactive oxygen species (ROS) assay and transmission electron microscopy (TEM) observation. In addition, theoretical calculation and molecular dynamics (MD) computation were used to illustrate the adsorption properties of different metal ion on NDs as well as release profile of ion from ND-ion complexes at different pH values.
\end{abstract}

Results: The adsorption capacity of NDs for different metal ions was different, and the adsorption for $\mathrm{Cu}^{2+}$ was the most strong among divalent metal ions. These different ND-ion complexes then had different cytotoxicity by influencing the subsequent cellular responses. Detailed investigation of $\mathrm{ND}-\mathrm{Cu}^{2+}$ interaction showed that the amount of released $\mathrm{Cu}^{2+}$ from ND-Cu ${ }^{2+}$ complexes at acidic lysosomal conditions was much higher than that at neutral conditions, leading to the elevation of intracellular ROS level, which triggered cytotoxicity. By theoretical approaches, we demonstrated that the functional carbon surface and cluster structures of NDs made them good vehicles for metal ions delivery.

Conclusions: NDs played the Trojan horse role by allowing large amounts of metal ions accumulate into living cells followed by subsequent release of ions in the interior of cells, which then led to cytotoxicity. The present experimental and theoretical results provide useful insight into understanding of cytotoxicity triggered by nanoparticle-ion interactions, and open new ways in the interpretation of nanotoxicity.

Keywords: Nanodiamonds, Trojan horse, Metal ion delivery, Experimental and theoretical approaches, pH-responsive ion release, Cytotoxicity

\footnotetext{
* Correspondence: zhuying@sinap.ac.cn

${ }^{\dagger}$ Equal contributors

Deceased

'Division of Physical Biology, and Bioimaging Center, Shanghai Synchrotron

Radiation Facility, Shanghai Institute of Applied Physics, Chinese Academy of Sciences, Shanghai 201800, China

Full list of author information is available at the end of the article
}

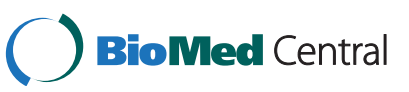

(c) 2015 Zhu et al.; licensee BioMed Central. This is an Open Access article distributed under the terms of the Creative Commons Attribution License (http://creativecommons.org/licenses/by/4.0), which permits unrestricted use, distribution, and reproduction in any medium, provided the original work is properly credited. The Creative Commons Public Domain Dedication waiver (http://creativecommons.org/publicdomain/zero/1.0/) applies to the data made available in this article, unless otherwise stated. 


\section{Background}

Since nanomaterials were discovered, a wide spectrum of them have been explored for applications in the delivery of various molecules with poor cell penetration. For example, Dai and co-workers showed that carboxylated carbon nanotubes can be conjugated with various proteins for intracellular protein delivery [1,2]. Mirkin et al. found that gold nanoparticles could introduce oligonucleotides into cells at a higher effective concentration than conventional transfection agents $[3,4]$. In addition, the utility of a number of nanomaterials as drug delivery platforms for water-insoluble drugs has been demonstrated [5-8]. However, few data are yet available concerning the nanoparticle-ion interactions and their bioeffects.

Nanodiamonds (NDs), a new member of nanocarbon allotropes with truncated octahedral architecture that are about 2 to $8 \mathrm{~nm}$ in diameter [9], integrate many of the requisite properties for various molecules delivery, including surface geometries that mediate high-affinity therapeutic binding, diversity of potential conjugates, scalability, and excellent biocompatibility [10,11]. Current researches focused on the delivery of various proteins $[12,13]$, genes [14-16], and drugs [17-20]. In addition to that, our previous work indicates that the cellular response of NDs in serum-free medium is related to the adsorption of sodium ions by NDs [21], yet the detailed adsorption mechanism and its universal applicability for other metal ion delivery remains unclear.

Here, we employed experimental approaches to investigate the various NDs-metal ion interactions and demonstrated that NDs acted as vehicles by allowing large amounts of metal ions accumulate into living cells followed by subsequent release of ions in the interior of cells, which then triggered cytotoxicity (Figure 1a). By theoretical approaches, the adsorption properties of different metal ion on NDs as well as release profile of ion from $\mathrm{ND}$-ion complexes at different $\mathrm{pH}$ values were well explored. A Trojan horse type effect has been proposed to explain the biological effects of nanoparticlebiomolecule interactions [22]. The present results are

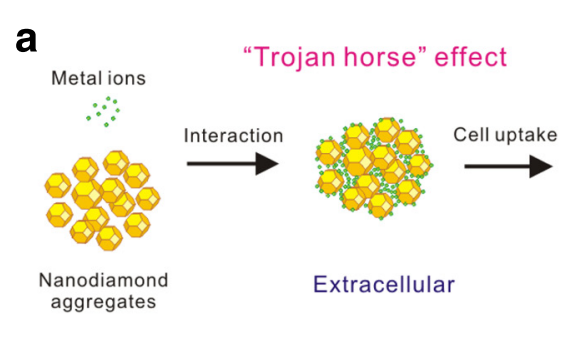

b
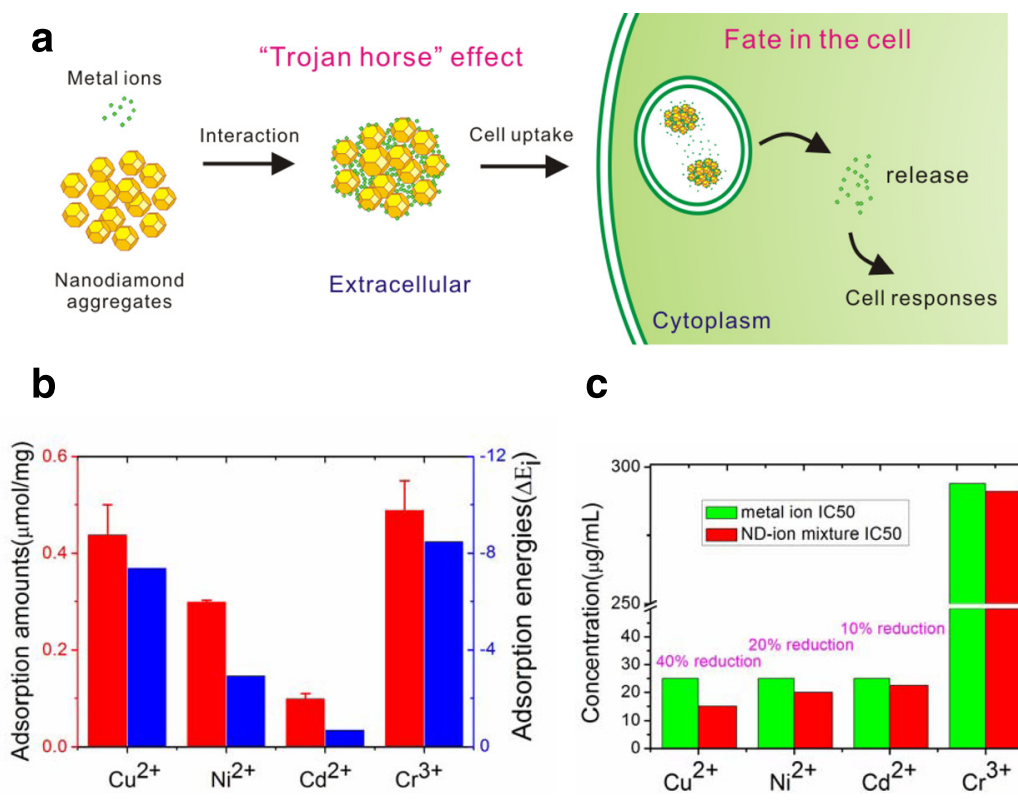

C
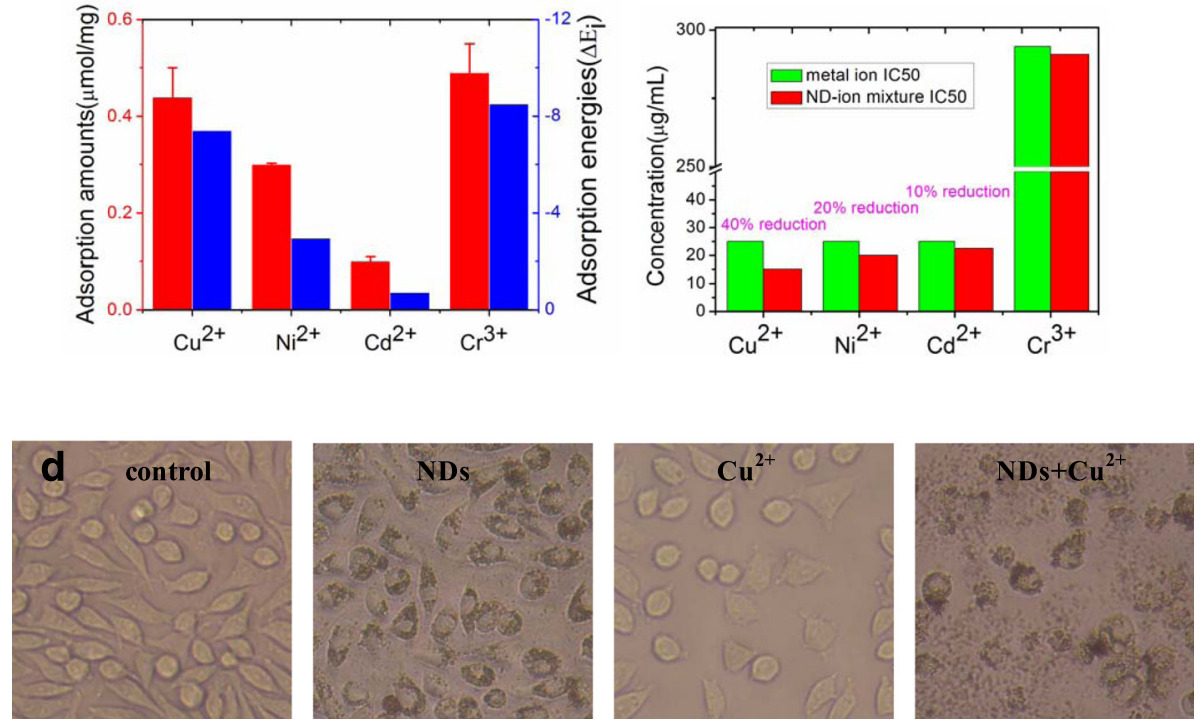

Figure 1 Interactions of NDs with metal ions trigger cytotoxicity. a: Scheme of adsorption of metal ions on NDs leads to cellular responses. b: The adsorption amounts (blue) and adsorption energies (red) of metal ions on NDs obtained by ICP-MS measurements and theoretical computation, respectively. c: The IC50 values of metal ions and ND-ion mixture and the differences between them. $\mathbf{d}$ : Optical images of L929 cells after incubation with $\mathrm{NDs}, \mathrm{Cu}^{2+}$ and $\mathrm{NDs}-\mathrm{Cu}^{2+}$ mixture for $24 \mathrm{~h}$. 
also in line with a Trojan horse-type mechanism, which opens new ways in the interpretation and understanding of nanoparticle-ion interactions and their bioeffects.

\section{Results and discussion}

NDs-metal ions interactions trigger cytotoxicity

To study the NDs-metal ions interactions, NDs were mixed for $2 \mathrm{~h}$ with $\mathrm{Cu}^{2+}, \mathrm{Ni}^{2+}, \mathrm{Cd}^{2+}$ and $\mathrm{Cr}^{3+}$, which are widely dispersed in the environment and interact with living systems result in toxic effects [23,24], respectively (reached the thermodynamic equilibrium. The mean adsorption amount of $\mathrm{Cu}^{2+}, \mathrm{Ni}^{2+}, \mathrm{Cd}^{2+}, \mathrm{Cr}^{3+}$ for per milligram NDs determined by inductively coupled plasma-mass spectrometry (ICP-MS) is $28.1,17.7,12.8$, and $25.6 \mu \mathrm{g}$, respectively (corresponding to $0.44,0.30,0.10$ and $0.49 \mu \mathrm{mol}$, respectively). Density-functional theory (DFT) calculations, which are widely used in the investigation of the interactions between nanoparticles and a variety of molecules $[25,26]$, have been used to illustrate the adsorption properties of each metal ion on NDs. An H-terminated diamond-structure nanoparticle, $\mathrm{C}_{35} \mathrm{H}_{38}$, one of the popular classic ND particle models $[27,28]$, is chosen as an example. Considering the NDs used in our work are functionalized with carboxyl $(-\mathrm{COOH})$ on the surface, two hydrogen atoms at the same side of the ND surface were replaced by the carboxyl (Additional file 1: Figure $\mathrm{S} 1 \mathrm{a}, \mathrm{b})$. The most probable schemes of metal ions attachment to the ND surface are via deprotonated carboxyl groups $\left(\mathrm{COO}^{-}\right)$[21] and each ND-ion complex with the most stable structure is shown in Additional file 1: Figure S1c-h. On this basis, the single-point with a polarizable continuum model (PCM) in water is performed to calculate the adsorption energies $[29,30]$. Interestingly, results also show that the adsorption energies of NDs for different ions are different, and the adsorption for $\mathrm{Cu}^{2+}$ is the most strong among divalent metal ions, which is in striking agreement with the experimental analysis results (Figure $1 \mathrm{~b}$ and Additional file 1: Table S1).

Our previous work indicates that large amount of sodium ions were adsorbed and delivered into the cell interior by NDs in serum-free medium, which led to obvious cell response [21]. Here, we evaluated the toxicity of ND-ion mixtures to explore whether the interaction of NDs with metal ions influenced the cellular responses. mouse fibroblast (L929) cells, which are widely used in metal ions cytotoxicity tests [31,32], were chosen as a research model. Cellular viability determination by 3-(4,5-dimethylthiazol-2-yl)-2,5-diphenyltetrazolium bromide (MTT) method shows that addition of NDs improved the metal ions induced toxicity to L929 cells with different extent (see Additional file 1: Figure S2) and the IC50 values of $\mathrm{Cu}^{2+}, \mathrm{Ni}^{2+}$ and $\mathrm{Cd}^{2+}$ decreased by approximately $40 \%, 20 \%$, and 10\%, respectively (Figure 1c), which has similar order to adsorption amount of each metal ion on NDs. For $\mathrm{Cr}^{3+}$, the adsorption amount is very similar to $\mathrm{Cu}^{2+}$, but the interaction of NDs with $\mathrm{Cr}^{3+}$ does not trigger increased cytotoxicity because cells are not sensitive to $\mathrm{Cr}^{3+}$ [the half maximal inhibitory concentration (IC 50) of $\mathrm{Cr}^{3+}$ is $294 \mu \mathrm{g} / \mathrm{mL}$, excelling that of other three metal ions by $\sim 12$ times]. The effect of ND-metal ion interaction on cellular responses was again confirmed when cell viability assessments were performed for another two cells [human bronchial epithelial (BEAS-2B) cells and human keratinocyte ( $\mathrm{HaCaT})$ cells] exposed to metal ions and ND-ion mixtures (see Additional file 1: Figure S3).

Since the delivery of $\mathrm{Cu}^{2+}$ by NDs leads to most obvious cellular responses, a detailed investigation of the interaction between NDs and $\mathrm{Cu}^{2+}$ is performed in the following experiment. From the kinetics curves and adsorption isotherm curves, we can see that large amounts of $\mathrm{Cu}^{2+}$ were adsorbed very rapidly by NDs, and saturation was achieved in less than $30 \mathrm{~min}$ (see Additional file 1: Figure S4). Optical microscopy (Figure 1d) images show that NDs were remarkably internalized and existed as dark granules in the cytoplasm. Addition of NDs improved the $\mathrm{Cu}^{2+}$ induced morphology changes and significantly reduced the cell number. Trypan blue exclusion test shows that addition of NDs decreased the cell viability from 52\% to $12 \%$, while cell survival of NDs alone was $96 \%$. We also examined the cell viability of other nanoparticle- $\mathrm{Cu}^{2+}$ mixture by typan blue exclusion test. Results show that cellular responses are more remarkable when $\mathrm{Cu}^{2+}$ was vectorized by NDs than by ultra-small graphene oxide (sGO) or nanocarbon blacks (CBs) with similar size (Figure 2 and Additional file 1: Figure S5, S6), indicating that the unique geometries of ND clusters play an important role. NDs dispersed in aqueous solution can

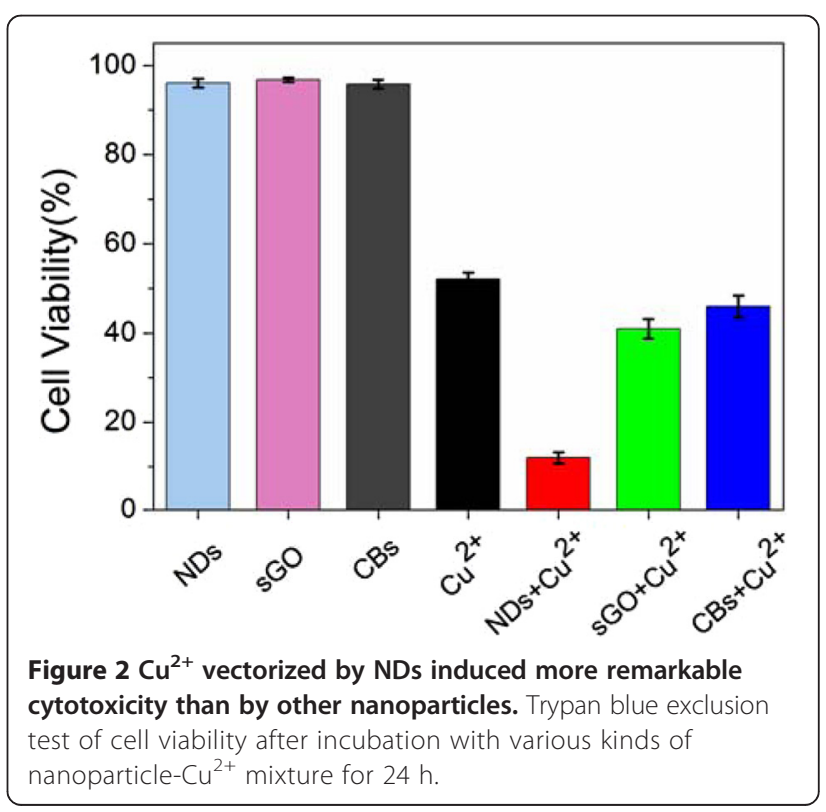


spontaneously form clusters with a lower free energy [33]. In our previous work [19], a model for the spatial configuration of ND clusters has been proposed. According to this model, it is speculated that metal ions can rapidly and freely diffuse along the nano-scaled pores of the ND cluster, leading to a relatively high adsorption capability.

\section{NDs- $\mathrm{Cu}^{2+}$ interactions determine their internalization fate}

Next, we used synchrotron-based scanning transmission $\mathrm{X}$-ray microscopy (STXM) and micro X-ray fluorescence $(\mu \mathrm{XRF})$ techniques to investigate the internalization fate of free $\mathrm{Cu}^{2+}$ and ND-Cu${ }^{2+}$ mixture. IC50 value of $\mathrm{Cu}^{2+}$ $(25 \mu \mathrm{g} / \mathrm{mL})$ calculated from Additional file 1: Figure S2 was chosen for the succedent observations. From STXM images of a typical cell, we observed a significant increase in the amount of intracellular $\mathrm{Cu}^{2+}$ when exposed to the ND-Cu${ }^{2+}$ mixture as compared with exposure to $\mathrm{Cu}^{2+}$ alone. (Figure 3a and Additional file 1: Figure S7). More importantly, it is found that for the NDs- $\mathrm{Cu}^{2+} \mathrm{ex}-$ posure groups, large amount of $\mathrm{Cu}^{2+}$ inside the cells were mainly attached to NDs, illustrating that $\mathrm{Cu}^{2+}$ entered the cells in the form of ND-Cu${ }^{2+}$ complexes. Another synchrotron-based $\mu \mathrm{XRF}$ experiment was performed to further examine the difference in intracellular $\mathrm{Cu}^{2+}$ concentration with or without NDs. Fluorescence spectra showed that cells cultured in medium containing $25 \mu \mathrm{g} / \mathrm{mL} \mathrm{Cu}^{2+}$ yielded a $\approx 18$ fold increase $\mathrm{Cu} \mathrm{Ka}$ signal at $8.05 \mathrm{KeV}$ compared with cells cultured in basal medium (see Additional file 1: Figure S8). Consistent with recent literature [34], we found that the total amount of $\mathrm{Zn}$ varied little in most of the samples and the $\mathrm{Zn}$ concentration followed the cell shape. Additionally, uptake of $\mathrm{NDs}-\mathrm{Cu}^{2+}$ complex may influence $\mathrm{Zn}$ ion level inside cells due to toxicity. Elemental maps of a typical cell showed that the $\mathrm{Cu}^{2+}$ concentration in cells treated with ND-Cu mixture was significantly higher than that in cells treated with $\mathrm{Cu}^{2+}$ alone, and no $\mathrm{Cu}^{2+}$ signal was detected in cells treated with NDs alone, which was consistent with that treated with basal medium (Figure 3b). Further transmission electron microscopy (TEM) observation as well as energy dispersive spectroscopy (EDS) analysis confirmed these X-ray imaging results (see Additional file 1: Figure S9). Moreover, both STXM and $\mu$ XRF images showed that addition of NDs made the $\mathrm{Cu}$-rich zone inside cells get more concentrated.

ICP-MS was used to quantitatively measure the difference in intracellular $\mathrm{Cu}^{2+}$ concentration. The amount of intracellular $\mathrm{Cu}^{2+}$ reached $384 \pm 74 \mathrm{ng}$ after exposure to $\mathrm{ND}-\mathrm{Cu}^{2+}$ mixture, whereas that was only $90 \pm 17$ ng after exposure to $\mathrm{Cu}^{2+}$ alone (Figure 3c). All these data demonstrated that large amounts of $\mathrm{Cu}^{2+}$ could be delivered into cell interior through loading on NDs.

\section{Release profile of $\mathrm{Cu}^{2+}$ from ND-Cu${ }^{2+}$ complex at different $\mathrm{pH}$ values}

Several studies have shown that NDs uptake in a variety of cells was by endocytosis [10,35]. After entering the cytoplasm of the cells, many of NDs often store in endosomes, which subsequently fuse with lysosomes that contain many different hydrolytic enzymes [36]. Thus, we then examined the release profile of $\mathrm{Cu}^{2+}$ from ND-Cu ${ }^{2+} \mathrm{com}-$ plex at extracellular $\mathrm{pH}$ (at typical cell culture medium $\mathrm{pH}$ of 7.4) and mildly acidic conditions (at typical lososomal $\mathrm{pH}$ of 5). The release curve (Figure 4a) showed that at neutral $\mathrm{pH}$, a very small amount of $\mathrm{Cu}^{2+}$ (only about $2 \%$ ) could release from ND-Cu ${ }^{2+}$ complex and confirmed the stability of ND-Cu ${ }^{2+}$ complex in cell culture medium. On the contrary, at acidic conditions, $\mathrm{Cu}^{2+}$ absorbed on NDs released very quickly. The amount of released $\mathrm{Cu}^{2+}$, presented by a weight percentage of the total $\mathrm{Cu}^{2+}$ adsorbed, was approximately 15 times higher than that at neutral conditions.

DFT calculations and molecular dynamics (MD) simulations are used to better understand these two different release behaviors. In the ND particle model $[27,28]$ (details see Additional file 1: Supplementary Method), carboxyl is protonated $(\mathrm{COOH})$ at low $\mathrm{pH}$ values and deprotonated (COO-) at high $\mathrm{pH}$ values (Figure $4 \mathrm{~b}$ and Additional file 1: Figure S10) [21]. The most stable structure of $\mathrm{ND}-\mathrm{Cu}^{2+}$ complex at low $\mathrm{pH}$ values (denoted by $\mathrm{NDH}-\mathrm{Cu}^{2+}$ ) is shown in Additional file 1: Figure S10. PCM in water mentioned above was performed to calculate the adsorption energies of $\mathrm{Cu}^{2+}$ on NDs. Results indicate that it is $-5.04 \mathrm{eV}$ at low $\mathrm{pH}$ values, which is much weaker than that $(-7.38 \mathrm{eV})$ at high $\mathrm{pH}$ values (Figure $1 \mathrm{~b}$ and Additional file 1: Table S2). During our 4 ns MD simulations, the mean adsorption number of $\mathrm{Cu}^{2+}$ on NDs is 25 at high $\mathrm{pH}$ values and 4 at low $\mathrm{pH}$ values (Figure 4c) (details see Additional file 1: Supplementary Method, Additional file 2 and Additional file 3). All of these theoretical outcomes are compatible with the experimental evidences.

"Trojan horse" effect has been proposed to explain the biological effects of nanoparticle-biomolecule interactions [22]. Our results can also be explained by similar mechanism. The cellular membrane is an evolutionary developed barrier for most ions, but nanoparticles can efficiently penetrate through this membrane. Once inside the cell, $\mathrm{Cu}^{2+}$ releases from ND-Cu ${ }^{2+}$ complex, especially at low $\mathrm{pH}$ within the lysosomes. This $\mathrm{pH}$-responsive ion release property provides new insights into interpretation and understanding of nanoparticle-ion interaction and their bioeffects.

\section{Enhancement of bioeffects by ND-vectorized $\mathrm{Cu}^{2+}$}

Reactive oxygen species (ROS) associated oxidative stress is the general pathway for $\mathrm{Cu}^{2+}$ to induce bioeffects $[37,38]$. We then determined the intracellular ROS 
a
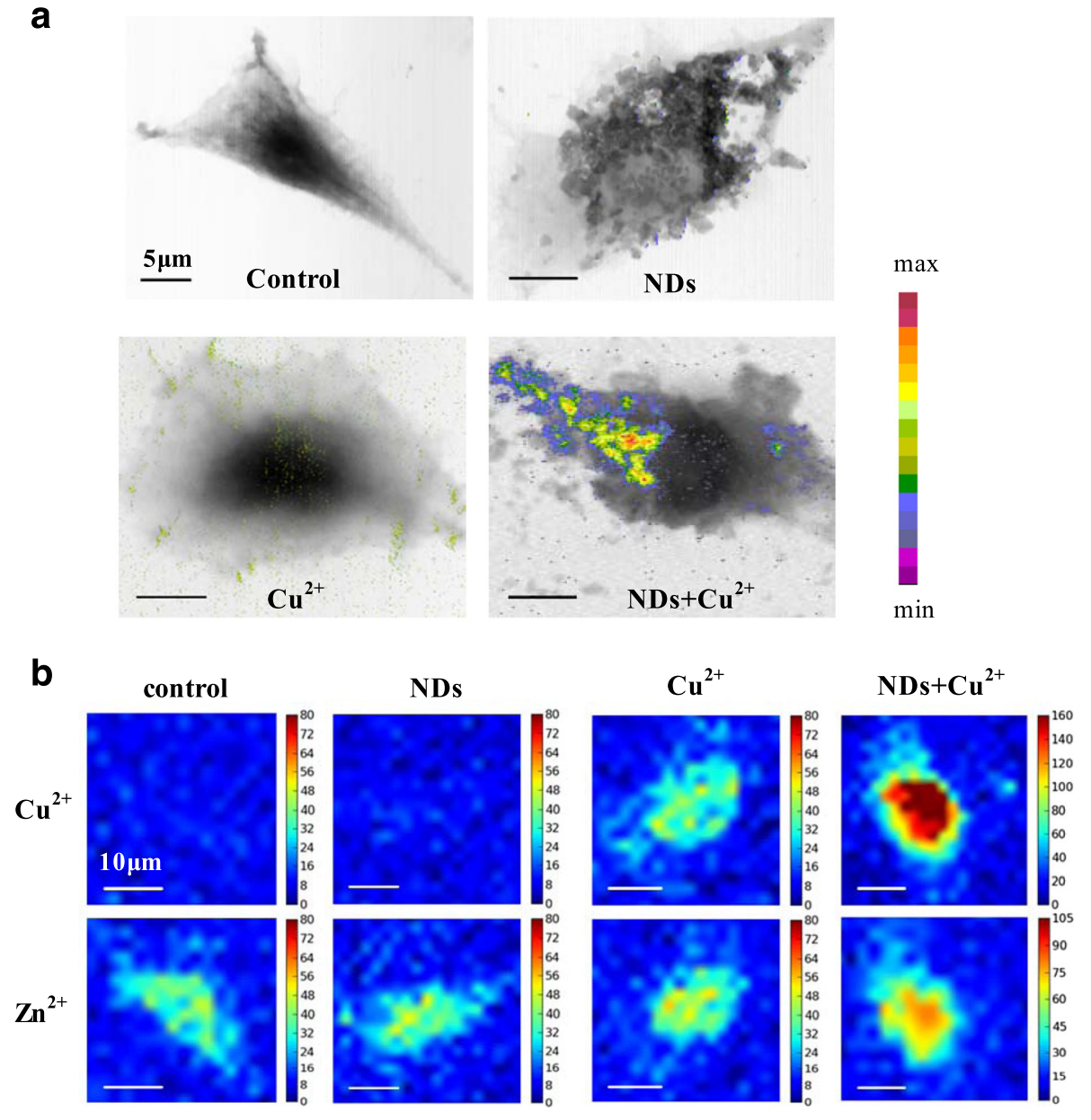

C

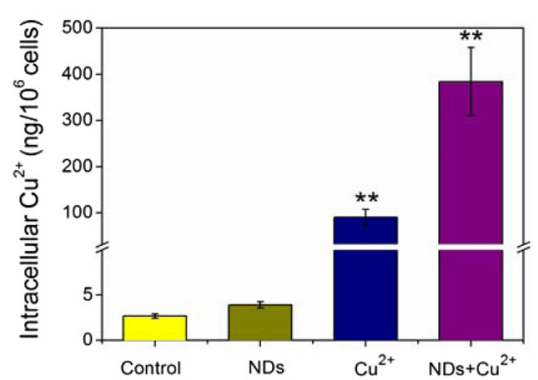

Figure 3 Interactions between NDs and $\mathrm{Cu}^{2+}$ determine their internalization fate. a: STXM images of copper distribution in a typical control L929 cell (top left), cell after incubation with NDs (top right), $\mathrm{Cu}^{2+}$ (bottom left), and NDs-Cu ${ }^{2+}$ mixture (bottom right) for $24 \mathrm{~h}$. The range of quantities noted by the color bar is from $3.2 \times 10^{-6}$ to $7.0 \times 10^{-6}$ in (top left), from $3.9 \times 10^{-6}$ to $7.2 \times 10^{-6}$ in (top right), from $2.4 \times 10^{-6}$ to $7.2 \times 10^{-6}$ in (bottom left) and from $6.5 \times 10^{-6}$ to $5.0 \times 10^{-5}$ in (bottom right). The scanning step was $50 \mathrm{~nm}$. b: Imaging of intracellular copper distribution by microXRF. Elemental maps of copper (upper) and zinc (lower) are drawn. The size of a pixel is $3 \mu \mathrm{m} \times 3 \mu \mathrm{m}$. c: Intracellular $\mathrm{Cu}^{2+}$ concentration determined by ICP-MS (**p $<0.01$, one-way ANOVA for comparison).

production to test whether this $\mathrm{ND}-\mathrm{Cu}^{2+}$ interaction mediated cellular responses occurred through ROS accumulation induced by excessive $\mathrm{Cu}^{2+}$. Cells were loaded with the ROS measuring probe dichlorofluorescin diacetate (DCFH-DA). Results showed that after 24. $\mathrm{h}$ incubation, $25 \mu \mathrm{g} / \mathrm{mL} \mathrm{Cu}^{2+}$ slightly increased the intracellular ROS production compared with that of control ( 2.9 times) and at the other two time points ( 2 and $6 \mathrm{~h}$ ), no significant increase in the intracellular ROS production was observed. However, when it is vectorized by NDs dramatically induced the production of ROS in time dependent manner, and the 


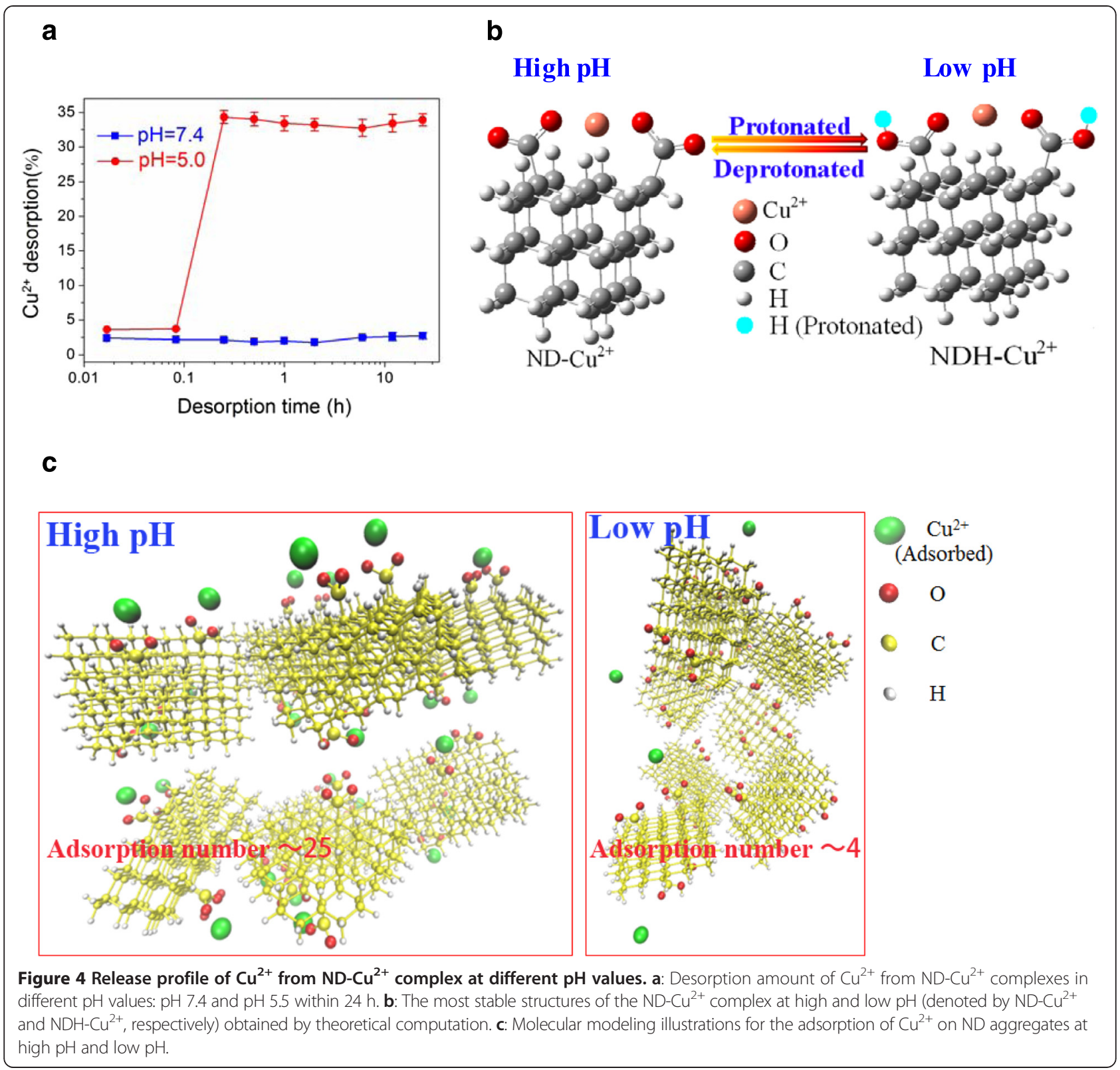

highest amount of ROS was generated after $24 \mathrm{~h}$ exposure, with $\sim 25$ fold increase over control (Figure $5 \mathrm{a}$ ). Furthermore, pretreatment with $\mathrm{N}$-Acetylcysteine (NAC, ROS scavenger [39]) for $2 \mathrm{~h}$ provided effective protection against $\mathrm{Cu}^{2+}$ induced ROS generation (Figure $5 \mathrm{~b}$ ).

Increased ROS generation has been suggested to associate well with cytotoxicity. TEM studies demonstrated that large amounts of NDs were internalized into cells and ND-vectorized $\mathrm{Cu}^{2+}$ lead to severe cell apoptosis and necrosis (Figure 5c). Quantitative flow cytometric analysis further showed that compared with $\mathrm{Cu}^{2+}$ exposure alone, the addition of NDs significantly enhanced the percentage of cells stained positive for 7-Amino-actinomycin
(7-AAD), indicating a loss of membrane integrity which is clearly suggestive of necrotic cell death (Figure $5 \mathrm{~d}$ ). However, after exposure to NDs alone, no significant increase in the percentage of cells stained positive for 7-AAD or Annexin V when compared to control. Taken together, our data indicated that large amounts of $\mathrm{Cu}^{2+}$ delivered into cells by NDs led to the elevation of intracellular ROS level, which triggered cytotoxicity.

Previous studies have indicated that in the synthesis of nanomaterials such as metal-containing fullerenes and carbon nanotubes, many metal impurities were also bioavailable at toxicologically significant concentrations despite metal bioavailability varied greatly from sample to 


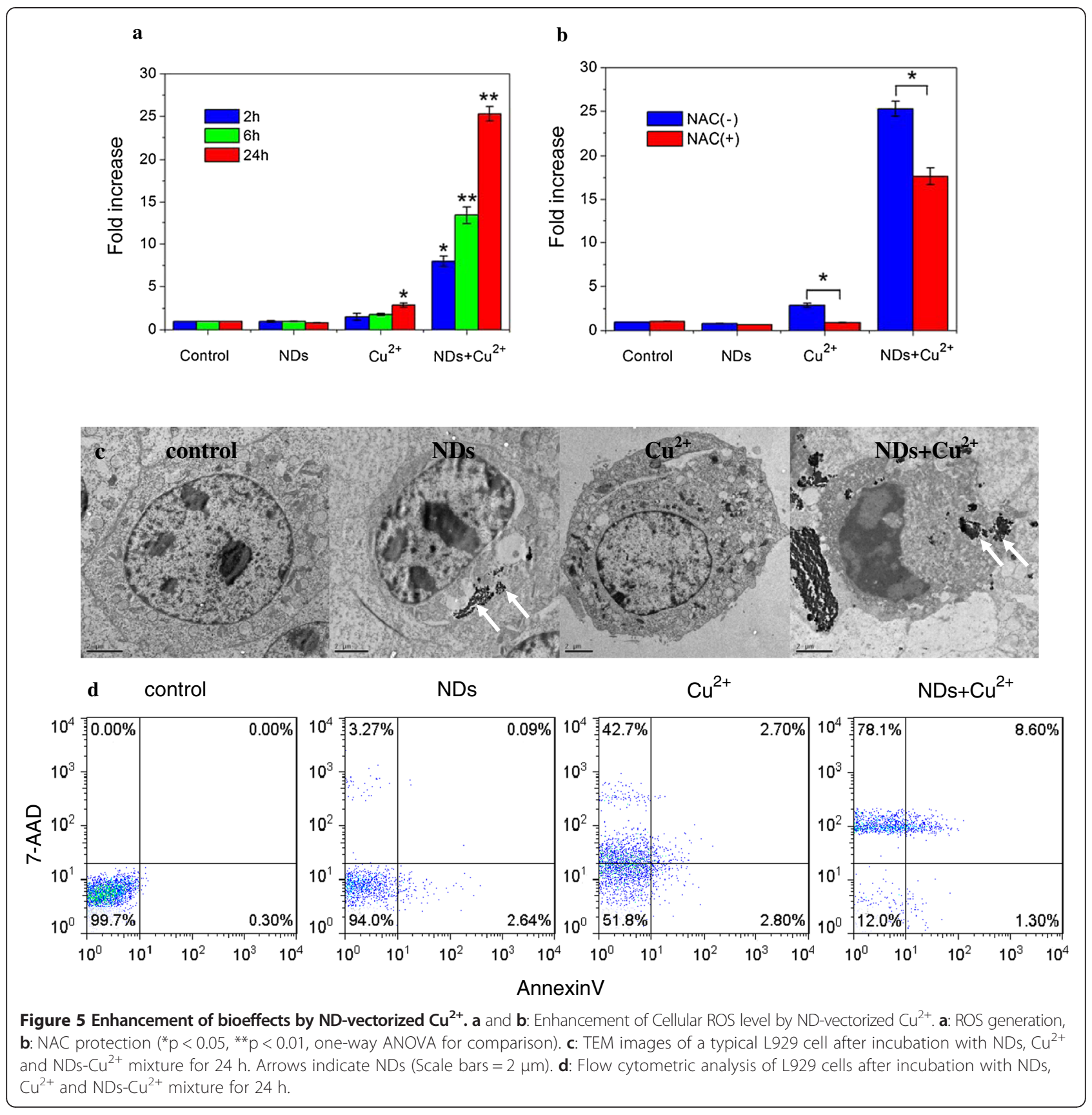

sample $[40,41]$. In this work, by using both experimental and theoretical approaches, we demonstrated the potential of NDs as vehicles for intracellular delivery of several kinds of metal ions. More importantly, detailed investigations of the interaction between NDs and $\mathrm{Cu}^{2+}$ as well as their bioeffects indicated that the released $\mathrm{Cu}^{2+}$ from ND$\mathrm{Cu}^{2+}$ complexes in the low-pH-intracellular environment led to the elevation of intracellular ROS level, which triggered cytotoxicity. All of these results suggest that we should pay more attention to the relative contributions of metal ions internalized by cells, through a Trojan horse mechanism, on overall cytotoxicity.

\section{Conclusions}

In conclusion, we have demonstrated the interactions between $\mathrm{NDs}$ and metal ions, $\mathrm{Cu}^{2+}, \mathrm{Ni}^{2+}, \mathrm{Cd}^{2+}$, and $\mathrm{Cr}^{3+}$, using both experimental and theoretical approaches. Results showed that adsorption capacity of NDs for different metal ions was different, and among them, the adsorption for $\mathrm{Cu}^{2+}$ was the most strong. These different ND-ion complexes had different cytotoxicity by influencing the subsequent cellular responses. Detailed investigation of cell responses of ND-Cu ${ }^{2+}$ complexes demonstrated that NDs played the Trojan horse role by allowing more $\mathrm{Cu}^{2+}$ accumulate into living cells followed by subsequent 
release of $\mathrm{Cu}^{2+}$ in the low-pH-intracellular environment leading to higher ROS level. These results provide therefore the evidence of the cytotoxicity triggered by nanoparticleion interactions, and surely open new ways in the interpretation and understanding of nanotoxicity.

\section{Methods}

\section{Materials}

NDs with individual sizes of $2-10 \mathrm{~nm}$ synthesized by detonation techniques were supplied by Gansu Gold Stone Nano. Material. Co. Ltd., China. They were easily dispersed in aqueous solution by sonication. Resultant suspensions were stable for extended periods of time. TEM images showed that the size of the majority of ND clusters was about 40-200 nm. The details for characterization have been described in our previous work [19].

Metal chlorides including $\mathrm{CuCl}_{2} \cdot 2 \mathrm{H}_{2} \mathrm{O}, \mathrm{NiCl}_{2} \cdot 6 \mathrm{H}_{2} \mathrm{O}$, $\mathrm{CdCl}_{2} \cdot 2.5 \mathrm{H}_{2} \mathrm{O}$, and $\mathrm{CrCl}_{3} \cdot 6 \mathrm{H}_{2} \mathrm{O}$ were obtained from Sigma-Aldrich, China. Stock solution of each metal ion was prepared with distilled millipore water and was used to make serial dilutions. All other chemicals used were of analytical grade.

\section{Determination of adsorption amount of each metal ion on NDs}

Each metal ion solution $(250 \mu \mathrm{g} / \mathrm{mL})$ was mixed thoroughly with the aqueous ND solution $(1 \mathrm{mg} / \mathrm{mL})$ for $2 \mathrm{~h}$ at $37^{\circ} \mathrm{C}$. After centrifugation at 13,000 rpm for $20 \mathrm{~min}$, the concentration of metal ions in the supernatant was determined by inductively coupled plasma-mass spectrometry (ICP-MS, $\mathrm{X}-7$, Thermo Elemental, USA). The amounts of metal ions adsorbed on the NDs were obtained by subtraction.

\section{Theoretical computational methods}

The B3LYP [42] method within generalized gradient approximation in the framework of DFT is employed to examine the intermolecular interactions between the ND particle and metal ions $\left(\mathrm{Cu}^{2+}, \mathrm{Ni}^{2+}, \mathrm{Cd}^{2+}\right.$ and $\left.\mathrm{Cr}^{3+}\right)$. The electron wave functions in the Gaussian function basis are used. We performed the optimized stationary points via the Berny algorithm [43]. For geometry optimization, we employed the double- $\zeta$ basis and added a diffuse function to the basis set, using a d-polarization function to carbon and oxygen atoms as well as one ppolarization function to the hydrogen atoms (marked with $6-31+G(d, p))$. At the same time, the pseudopotential function with Lanl2dz was introduced into the basis set for each metal ion. Furthermore, the singlepoints at this method with a PCM [30] in water were performed to show the solution effects. The adsorption energy of each metal ion on a single ND or NDH particle $\left(\Delta \mathbf{E}_{\mathrm{i}}\right)$ was defined as:

\section{$\Delta E_{i}=E_{N D-i}-E_{N D}-E_{i}$}

where $\mathbf{E}_{\mathrm{ND}-\mathrm{i}}, \mathbf{E}_{\mathrm{ND}}$, and $\mathbf{E}_{\mathrm{i}}$ are total energy of metal ions adsorbed on a single ND particle, a single ND particle and metal ions, respectively. All calculations were carried out using the Gaussian-09 package [44].

\section{Cytotoxicity assessment of metal ions and metal-ion mixtures}

L929 cells were grown in RPMI-1640 (Gibco) cell culture medium supplemented with $10 \%$ fetal bovine serum (FBS), and the resultant cell suspension $\left(7 \times 10^{4}\right.$ cells $\left./ \mathrm{mL}\right)$ was dispensed into 24-well plates and incubated overnight to allow for cell adherence. After washing twice with phosphate buffered saline (PBS), cells were treated with $\mathrm{Cu}^{2+}(0$ to $40 \mu \mathrm{g} / \mathrm{mL}$ ), $\mathrm{Ni}^{2+}$ (0 to $40 \mu \mathrm{g} / \mathrm{mL}$ ), $\mathrm{Cd}^{2+}(0$ to $30 \mu \mathrm{g} / \mathrm{mL}$ ), $\mathrm{Cr}^{3+}$ (0 to $400 \mu \mathrm{g} / \mathrm{mL}$ ) with or without $50 \mu \mathrm{g} / \mathrm{mL}$ NDs for $24 \mathrm{~h}$. Cells incubated with the complete culture medium were used as controls. For ND-metal ion mixture samples, each kind of metal ion solution was mixed thoroughly with the aqueous ND solution for $2 \mathrm{~h}$ prior to experiments. Cell viability was determined by the MTT (Sigma-Aldrich, Shanghai, China) assay. The cell viabilities were expressed as a percentage of $\mathrm{OD}_{\text {test }} / \mathrm{OD}_{\text {control. }}$. All of the viability assessment data was based on three independent measurements. The IC 50 value of each metal ion and NDs-ion mixture was determined by Origin Pro 7.5 software.

BEAS-2B cells were grown in RPMI-1640 cell culture medium supplemented with $10 \% \mathrm{FBS}$. HaCaT cells were grown in DMEM (Gibco) cell culture medium supplemented with $15 \%$ FBS. Cells were exposed to $50 \mu \mathrm{g} / \mathrm{mL}$ NDs, $25 \mu \mathrm{g} / \mathrm{mL} \mathrm{Cu}{ }^{2+}, 25 \mu \mathrm{g} / \mathrm{mL} \mathrm{Ni}^{2+}$ (IC50 value of each metal ion for $\mathrm{L} 929$ cells), $\mathrm{NDs}-\mathrm{Cu}^{2+}$ mixture and $\mathrm{NDs}-\mathrm{Ni}^{2+}$ mixture for $24 \mathrm{~h}$, respectively. The toxicity of these kinds of metal ions and metal-ion mixtures to BEAS-2B and $\mathrm{HaCaT}$ cells was determined using the same method as described above. All of these cell lines were selected based on their common use in metal ions cytotoxicity tests. In addition, they are nontumorogenic $[31,32,45,46]$.

\section{Cytotoxicity assessment of $\mathrm{Cu}^{2+}$ and NDs- $\mathrm{Cu}^{2+}$ mixture}

A L929 cell suspension $\left(7 \times 10^{4}\right.$ cells $\left./ \mathrm{mL}\right)$ was dispensed into 24-well plates and incubated overnight to allow for cell adherence. After washing twice with PBS, $50 \mu \mathrm{g} / \mathrm{mL}$ NDs, $25 \mu \mathrm{g} / \mathrm{mL} \mathrm{Cu}^{2+}$ (IC50 value) and NDs-Cu ${ }^{2+}$ mixture were added into the plate wells. Cells incubated with the complete culture medium were used as controls. Following $24 \mathrm{~h}$ incubation, the cell morphology changes were observed and recorded using an Olympus CKX41SF inverted optical microscope at $200 \times$ magnification. Cell aliquots were collected and immediately stained with trypan blue for $5 \mathrm{~min}$. Cell proliferation was measured by counting cell 
numbers and cell viabilities were expressed as a percentage of Number $_{\text {test }} /$ Number $_{\text {control. }}$.

In flow cytometric assays, cells were seeded in 6-well plates. After exposure to NDs, $\mathrm{Cu}^{2+}$ and NDs-Cu ${ }^{2+}$ mixture for $24 \mathrm{~h}$, cells were stained as described in the methods for using the BD FACSArrayTM Bioanlysis (BD Biosciences). Apoptotic cells were quantitated with APC-labeled Annexin V and the vital dye 7-AAD.

\section{Observation of $\mathrm{Cu}^{2+}$ delivery into the cells by NDs}

To observe the NDs as vehicles for intracellular $\mathrm{Cu}^{2+}$ delivery by STXM techniques, the $\mathrm{Si}_{3} \mathrm{~N}_{4}$ windows (100 $\mathrm{nm}$ thickness) were previously put into 24-well plates and sterilized by ultraviolet rays. A L929 cell suspension $\left(7 \times 10^{4}\right.$ cells $\left./ \mathrm{mL}\right)$ was dispensed into 24 -well plates and incubated overnight to allow for cell adherence to the $\mathrm{Si}_{3} \mathrm{~N}_{4}$ windows. $\mathrm{NDs}, \mathrm{Cu}^{2+}$ and $\mathrm{NDs}-\mathrm{Cu}^{2+}$ mixture were added into the designated wells by the same method as described above, and the cells were incubated for $24 \mathrm{~h}$ and then fixed with a few of $4 \%$ paraformaldehyde in 0.1M PBS. After wash with PBS, the cells were then dehydrated in a graded gradient ethanol series and dried under air. The ratio-contrast imaging of dual-energy absorption for copper mapping was performed at the beamline BL08U1 of Shanghai Synchrotron Radiation Facility (SSRF). A Fresnel zone plate focuses mono-energetic Xrays provided by SX700 monochromator and the focal beam point is $30 \mathrm{~nm}$ in diameter. Two photon energies were chosen, $\mathrm{E} 1=936.6 \mathrm{eV}$ and $\mathrm{E} 2=934 \mathrm{eV}$, which are just above and below the absorption edge of copper, to scan the sample pixel by pixel. A K-edge division method [47] was applied to obtain the overlay of absorption-contrast images of cells and copper distribution images.

Another synchrotron-based $\mu$ XRF microscopy was used to further verify the difference in intracellular $\mathrm{Cu}^{2+}$ concentration with or without NDs. The Mylar X-ray films (Hoffman, $12 \mu \mathrm{m}$ thickness) were previously put into 24-well plates and sterilized by successive baths in $70 \%$ ethanol. A L929 cell suspension $\left(7 \times 10^{4}\right.$ cells $\left./ \mathrm{mL}\right)$ was dispensed into 24-well plates and incubated overnight to allow for cell adherence to the thin films. NDs, $\mathrm{Cu}^{2+}$ and $\mathrm{NDs}-\mathrm{Cu}^{2+}$ mixture were added to the designated wells by the same method as described above. Following incubation, cells were washed with PBS and fixed with ice cold $80 \%$ ethanol. After excess ethanol had evaporated, the $\mu \mathrm{XRF}$ microscopy was performed at the beamline BL15U1 of SSRF. Incident $\mathrm{x}$-rays energy of 10 $\mathrm{keV}$, obtained with a Si (111) monochromator, was chosen in order to excite the K-lines of X-ray fluorescence of elements from $\mathrm{P}$ to $\mathrm{Zn}$. A light microscope was coupled to a computer for sample viewing and the sample platform was moved by a motorized X-ray mapping stage. A Kirkpatrick-Baez mirror system focused the $\mathrm{x}$-ray beam to a spot size of $3 \mu \mathrm{m} \times 3 \mu \mathrm{m}$ on the specimen, which was raster-scanned. XRF from the specimen was captured with an energy dispersive silicon drift detector (Vortex, USA). From the analysis of the X-ray fluorescence spectrum for each pixel, a spatial image can be obtained for each element separately. Such an image represents a two-dimensional projection of the volumetric distribution of the elements. The vertical and horizontal pixel size was $2 \mu \mathrm{m}$ each. Data collection time for each pixel was $4 \mathrm{~s}$ and fitting of the fluorescence data has been performed in batch processing using the PyMca 4.0.9 software [48]. Three cells in each sample were scanned and images of a typical cell were shown.

\section{Determination the intracellular $\mathrm{Cu}^{2+}$ concentration} Cells were treated with NDs, $\mathrm{Cu}^{2+}$ and $\mathrm{NDs}-\mathrm{Cu}^{2+}$ mixture by the same method as mentioned above. Cells without any treatment were used as controls. After incubation, all samples were washed thoroughly with PBS for three times and cells were trypsinized, collected and transferred to Enppendorf tubes. Aliquots of $100 \mu \mathrm{l}$ were taken from the each sample to determine the number of cells, and the remainder of the cell suspensions was sonicated for 3-5 min. The cell supernatant after sonication was digested for $12 \mathrm{~h}$ by $2 \%$ nitric acid and then analyzed the $\mathrm{Cu}^{2+}$ concentration by ICP-MS.

\section{Desorption of $\mathrm{Cu}^{2+}$ from NDs-Cu${ }^{2+}$ complexes}

$\mathrm{NDs}-\mathrm{Cu}^{2+}$ complexes were prepared by the same method as described in "adsorption of metal ions on NDs" section. After gentle wash with millipore water, the $\mathrm{NDs}-\mathrm{Cu}^{2+}$ complexes were resuspended in PBS solution at $\mathrm{pH} 7.4$ and $\mathrm{pH} 5.0$, respectively. Following sonication, the mixture was put aside over the course of $24 \mathrm{~h}$. At a given interval time, mixtures were centrifuged at 13,000 rpm for $20 \mathrm{~min}$ and the concentration of $\mathrm{Cu}^{2+}$ in the supernatant was determined by ICP-MS. The variation of desorption amounts with the elapsed times gave release curve of $\mathrm{Cu}^{2+}$ from $\mathrm{NDs}-\mathrm{Cu}^{2+}$ complex.

\section{Determination of intracellular reactive oxygen species}

level

Cells were treated with NDs, $\mathrm{Cu}^{2+}$ and NDs- $\mathrm{Cu}^{2+}$ mixture as mentioned above. Cells without any treatment were used as controls. After 2, 6, and $24 \mathrm{~h}$ incubation, cells were washed with PBS and loaded with DCFH-DA $(5 \mu \mathrm{M})$ from Reactive Oxygen Species Assay Kit (Beyotime Institute of Biotechnology, Jiangsu, China) for $40 \mathrm{~min}$. After a further wash with PBS, cell suspensions were collected into 96-well flat bottom black plate to determine the relative fluorescent intensity (RFI, $\lambda_{\mathrm{ex}} 485 \mathrm{~nm}, \lambda_{\mathrm{em}} 535$ $\mathrm{nm})$ by Tecan GENios fluorescence microplate reader. The RPMI-1640 medium was used as blank. The RFI over control was calculated as the measured ROS levels. 
In order to observe the protection effect of NAC, an antioxidant agent, against oxidative stress induced by $\mathrm{Cu}^{2+}$, cells were pretreated with NAC (Sigma-Aldrich, China, $10 \mathrm{mM}$ ) for $2 \mathrm{~h}$. After wash with PBS for three times, cells were treated with $\mathrm{NDs}, \mathrm{Cu}^{2+}$ and $\mathrm{NDs}-\mathrm{Cu}^{2+}$ mixture for $24 \mathrm{~h}$. Cells without any treatment were used as controls. The subsequent DCFH-DA loading and intracellular RFI determination were conducted using the methods mentioned above.

\section{TEM observation}

After exposing L929 cells to NDs, $\mathrm{Cu}^{2+}$ and ND-Cu${ }^{2+}$ mixture for $24 \mathrm{~h}$, the cells were washed twice with PBS, and prefixed with a few of $2.5 \%$ glutaraldehyde in $0.1 \mathrm{M}$ PBS. Then, the cells were collected using a cell scraper and centrifuged at $2000 \mathrm{rpm}$ for $10 \mathrm{~min}$. Cell aggregates were fixed in $2.5 \%$ glutaraldehyde for at least $2 \mathrm{~h}$. After a further wash with PBS, the cells were then dehydrated in a graded gradient ethanol series and embedded in Epon618. Ultrathin sections of the embedded cells were then examined by TEM.

\section{Statistical analysis}

All results are expressed as the mean \pm standard deviation from triplicate experiments performed in a parallel manner unless otherwise indicated. Statistical significance of the data was determined by $t$-tests or one-way analysis of variance (ANOVA) using SPSS 11.5. ${ }^{* *}$ equals $\mathrm{P}<0.01$; * equals $\mathrm{P}<0.05$.

\section{Additional files}

Additional file 1: Supplementary information.

Additional file 2: Movie of Cu2+ adsorption on the ND particles.

Additional file 3: Movie of Cu2+ adsorption on the NDH particles.

\section{Abbreviations}

NDs: Nanodiamonds; L929: Mouse fibroblast cells; MTT: 3-(4,5-dimethylthiazol-2yl)-2,5-diphenyltetrazolium bromide; BEAS-2B: Human bronchial epithelial cells; HaCaT: Human keratinocyte cells; STXM: Scanning transmission X-ray microscopy; HXRF: Micro X-ray fluorescence microscopy; ICP-MS: Inductively coupled plasma-mass spectrometry; ROS: Reactive oxygen species; TEM: Transmission electron microscopy; MD: Molecular dynamics; DFT: Density-functional theory; PCM: Polarizable continuum model; IC50: Half maximal inhibitory concentration of a substance; $5 \mathrm{GO}$ : Ultra-small graphene oxide; CBs: Nanocarbon blacks; EDS: Energy dispersive spectroscopy; DCFH-DA: Dichlorofluorescin diacetate; NAC: N-Acetylcysteine; 7-AAD: 7-Amino-actinomycin; FBS: Fetal bovine serum; PBS: Phosphate buffered saline; SSRF: Shanghai Synchrotron Radiation Facility.

\section{Competing interests}

The authors declare that they have no competing interests.

\section{Authors' contributions}

YZ and QH conceived and designed the experiments. YZ, YuZ and JZ performed the experiments, GS and JY performed the theoretical work. WL helped in guidance of adsorption experiments. AL and RT helped in quidance of synchrotron-based X-ray microscopy. YZ, YuZ and GS wrote the paper. HF, CF and $\mathrm{QH}$ performed critical revisions. All authors discussed and commented on the manuscript. All authors read and approved the final manuscript.

\section{Acknowledgements}

We thank Yan Peng from Gansu Gold Stone Nano. Material Co. Ltd for kindly providing nanodiamonds and Longqiang Wang from Degussa China for kindly providing nanocarbon blacks. This work was supported financially by the Ministry of Science and Technology of China (2012CB825805, 2012CB932600, 2012CB932400), the National Natural Science Foundation of China (21390414, U1332119, 11275251, U1232113, 11290164 and 11179004), Shanghai Rising-Star Program (14QA1404400). The authors acknowledge the Supercomputer Center of Chinese Academy of Sciences and the Shanghai Supercomputer Center of China for computational resources.

We would like to dedicate this paper to Prof. Qing Huang, who unfortunately passed away just before this paper could be published. Qing played an essential role in the research described here and he is greatly missed.

\section{Author details}

'Division of Physical Biology, and Bioimaging Center, Shanghai Synchrotron Radiation Facility, Shanghai Institute of Applied Physics, Chinese Academy of Sciences, Shanghai 201800, China. ${ }^{2}$ Graduate School of the Chinese Academy of Sciences, Beijing 100049, China. ${ }^{3}$ Laboratory of Water Science and Technology, Shanghai Institute of Applied Physics, Chinese Academy of Sciences, Shanghai 201800, China. ${ }^{4}$ Shanghai Synchrotron Radiation Facility, Shanghai 201203, China. ${ }^{5}$ School of Life Science and Technology,

ShanghaiTech University, Shanghai 200031, China.

Received: 4 June 2014 Accepted: 11 December 2014

Published online: 05 February 2015

\section{References}

1. Kam NWS, Jessop TC, Wender PA, Dai HJ. Nanotube molecular transporters: internalization of carbon nanotube-protein conjugates into mammalian cells. J Am Chem Soc. 2004;126:6850-1.

2. Kam N, Dai H. Carbon nanotubes as intracellular protein transporters: generality and biological functionality. J Am Chem Soc. 2005;127:6021-6.

3. Rosi NL, Giljohann DA, Thaxton CS, Lytton-Jean AKR, Han MS, Mirkin CA. Oligonucleotide-modified gold nanoparticles for intracellular gene regulation. Science. 2006;312:1027-30.

4. Jensen SA, Day ES, Ko CH, Hurley LA, Luciano JP, Kouri FM, et al. Spherical nucleic acid nanoparticle conjugates as an RNAi-based therapy for glioblastoma. Sci Transl Med. 2013;5:209ra152.

5. Peer D, Karp JM, Hong S, FaroKHzad OC, Margalit R, Langer R. Nanocarriers as an emerging platform for cancer therapy. Nat Nanotechnol. 2007;2:751-60.

6. Liu Z, Sun X, Nakayama-Ratchford N, Dai H. Supramolecular chemistry on water-soluble carbon nanotubes for drug loading and delivery. ACS Nano. 2007;1:50-6.

7. Cheng K, Peng S, Xu CJ, Sun SH. Porous hollow Fe3O4 nanoparticles for targeted delivery and controlled release of cisplatin. J Am Chem Soc. 2009;131:10637-44.

8. Kim H, Lee D, Kim J, Kim TI, Kim WJ. Photothermally triggered cytosolic drug delivery via endosome disruption using a functionalized reduced graphene oxide. ACS Nano. 2013;7:6735-46.

9. Danilenko W. On the history of the discovery of nanodiamond synthesis. Phys Solid State. 2004:46:595-9.

10. Schrand A, Huang H, Carlson C, Schlager J, Osawa E, Hussain S, et al. Are diamond nanoparticles cytotoxic? J Phys Chem B. 2007;111:2-7.

11. Mochalin VN, Shenderova O, Ho D, Gogotsi Y. The properties and applications of nanodiamonds. Nat Nanotechnol. 2012;7:11-23.

12. Huang LCL, Chang HC. Adsorption and immobilization of cytochrome $\mathrm{c}$ on nanodiamonds. Langmuir. 2004;20:5879-84.

13. Perevedentseva E, Cheng C, Chung P, Tu J, Hsieh Y, Cheng C. The interaction of the protein lysozyme with bacteria E. coli observed using nanodiamond labelling. Nanotechnol. 2007;18:315102-8.

14. Zhang $X Q$, Chen M, Lam R, Xu XY, Osawa E, Ho D. Polymer-functionalized nanodiamond platforms as vehicles for gene delivery. ACS Nano. 2009;3:2609-16.

15. Chen M, Zhang XQ, Man HB, Lam R, Chow EK, Ho DA. Nanodiamond vectors functionalized with polyethylenimine for siRNA delivery. J Phys Chem Lett. 2010;1:3167-71.

16. Alhaddad A, Adam M-P, Botsoa J, Dantelle G, Perruchas S, Gacoin T, et al. Nanodiamond as a vector for siRNA delivery to Ewing sarcoma cells. Small. 2011;7:3087-95. 
17. Huang H, Pierstorff E, Osawa E, Ho D. Active nanodiamond hydrogels for chemotherapeutic delivery. Nano Lett. 2007;7:3305-14.

18. Chen M, Pierstorff E, Lam R, Li S, Huang H, Osawa E, et al. Nanodiamondmediated delivery of water-insoluble therapeutics. ACS Nano. 2009;3:2016-22

19. Li J, Zhu Y, Li WX, Zhang XY, Peng Y, Huang Q. Nanodiamonds as intracellular transporters of chemotherapeutic drug. Biomaterials. 2010;31:8410-8.

20. Chow EK, Zhang XQ, Chen M, Lam R, Robinson E, Huang HJ, et al. Nanodiamond therapeutic delivery agents mediate enhanced chemoresistant tumor treatment. Sci Transl Med. 2011;3:73ra21.

21. Zhu Y, Li W, Zhang Y, Li J, Liang L, Zhang $X$, et al. Excessive sodium ions delivered into cells by nanodiamonds: implications for tumor therapy. Small. 2012;8:1771-9.

22. Hurt RH, Monthioux M, Kane A. Toxicology of carbon nanomaterials: Status, trends, and perspectives on the special issue. Carbon. 2006:44:1028-33.

23. Morselli L, Olivieri P, Brusori B, Passarini F. Soluble and insoluble fractions of heavy metals in wet and dry atmospheric depositions in Bologna, Italy. Environ Pollut. 2003:124:457-69.

24. Azimi S, Ludwig A, Thevenot DR, Colin JL. Trace metal determination in total atmospheric deposition in rural and urban areas. Sci Total Environ. 2003;308:247-56.

25. Wong-Ekkabut J, Baoukina S, Triampo W, Tang IM, Tieleman DP, Monticelli L. Computer simulation study of fullerene translocation through lipid membranes. Nat Nanotechnol. 2008:3:363-8.

26. Qin W, Li X, Bian WW, Fan XJ, Qi JY. Density functional theory calculations and molecular dynamics simulations of the adsorption of biomolecules on graphene surfaces. Biomaterials. 2010;31:1007-16.

27. Drummond ND, Williamson AJ, Needs RJ, Galli G. Electron emission from diamondoids: a diffusion quantum Monte Carlo study. Phys Rev Lett. 2005;95:096801.

28. Saani MH, Kargarian M, Ranjbar A. Comparison between stability, electronic, and structural properties of cagelike and spherical nanodiamond clusters. Phys Rev B. 2007;76:035417.

29. Cammi R, Mennucci B, Tomasi J. Fast evaluation of geometries and properties of excited molecules in solution: a Tamm-Dancoff model with application to 4-dimethylaminobenzonitrile. J Phys Chem A. 2000;104:5631-7.

30. Cossi M, Scalmani G, Rega N, Barone V. New developments in the polarizable continuum model for quantum mechanical and classical calculations on molecules in solution. J Chem Phys. 2002;117:43-54.

31. Elshahawy WM, Watanabe I, Kramer P. In vitro cytotoxicity evaluation of elemental ions released from different prosthodontic materials. Dent Mater. 2009;25:1551-5.

32. Okazaki Y, Gotoh E. Metal ion effects on different types of cell line, metal ion incorporation into L929 and MC3T3-E1 cells, and activation of macrophage-like J774.1 cells. Mat Sci Eng C-Mater. 2013;33:1993-2001.

33. Zhu Y, Li J, Li WX, Zhang Y, Yang XF, Chen N, et al. The biocompatibility of nanodiamonds and their application in drug delivery systems. Theranostics 2012:2:302-12.

34. Yang LC, MCRae R, Henary MM, Patel R, Lai B, Vogt S, et al. Imaging of the intracellular topography of copper with a fluorescent sensor and by synchrotron x-ray fluorescence microscopy. Proc Natl Acad Sci U S A. 2005;102:11179-84.

35. Chang YR, Lee HY, Chen K, Chang CC, Tsai DS, Fu CC, et al. Mass production and dynamic imaging of fluorescent nanodiamonds. Nat Nanotechnol. 2008;3:284-8.

36. Schrand AM, Lin JB, Hens SC, Hussain SM. Temporal and mechanistic tracking of cellular uptake dynamics with novel surface fluorophore-bound nanodiamonds. Nanoscale. 2011;3:435-45.

37. Mookerjee A, Basu JM, Majumder S, Chatterjee S, Panda GS, Dutta P, et al. A novel copper complex induces ROS generation in doxorubicin resistant Ehrlich ascitis carcinoma cells and increases activity of antioxidant enzymes in vital organs in vivo. BMC Cancer. 2006;6:267.

38. Yu YP, Lei P, Hu J, Wu WH, Zhao YF, Li YM. Copper-induced cytotoxicity: reactive oxygen species or islet amyloid polypeptide oligomer formation Chem Commun (Cambridge, U K). 2010;46:6909-11.

39. Friday E, Koshy N, Bhanderi VK, Torturro F. Effect of antioxidant N-acetylcysteine treatment on the phenotype of the TCL-1 transgenic mouse model of B-CLL through Reactive Oxygen Species (ROS) modulation. Blood. 2010;116:1475.

40. Liu XY, Gurel V, Morris D, Murray DW, Zhitkovich A, Kane AB, et al. Bioavailability of nickel in single-wall carbon nanotubes. Adv Mater. 2007:19:2790.

41. Hull MS, Kennedy AJ, Steevens JA, Bednar AJ, Weiss CA, Vikesland PJ. Release of metal impurities from carbon nanomaterials influences aquatic toxicity. Environ Sci Technol. 2009;43:4169-74.
42. Becke AD. Density-functional exchange-energy approximation with correct asymptotic-behavior. Phys Rev A. 1988;38:3098-100.

43. Peng CY, Ayala PY, Schlegel HB, Frisch MJ. Using redundant internal coordinates to optimize equilibrium geometries and transition states. J Comput Chem. 1996;17:49-56

44. Frisch MJ, Trucks GW, Schlegel HB, Scuseria GE, Robb MA, Cheeseman JR, et al. Gaussian 09, Revision A. 1, Gaussian, Inc., Wallingford, CT. 2009.

45. Liu R, France B, George S, Rallo R, Zhang HY, Xia T, et al. Association rule mining of cellular responses induced by metal and metal oxide nanoparticles. Analyst. 2014;139:943-53.

46. Ermolli M, Menne C, Pozzi G, Serra MA, Clerici LA. Nickel, cobalt and chromium-induced cytotoxicity and intracellular accumulation in human hacat keratinocytes. Toxicology. 2001:159:23-31.

47. Zhang XZ, Xu ZJ, Tai RZ, Zhen XJ, Wang Y, Guo Z, et al. Ratio-contrast imaging of dual-energy absorption for element mapping with a scanning transmission X-ray microscope. J Synchrotron Radiat. 2010;17:804-9.

48. Sole VA, Papillon E, Cotte M, Walter P, Susini J. A multiplatform code for the analysis of energy-dispersive X-ray fluorescence spectra. Spectrochim Acta B. 2007:62:63-8.

\section{Submit your next manuscript to BioMed Central and take full advantage of:}

- Convenient online submission

- Thorough peer review

- No space constraints or color figure charges

- Immediate publication on acceptance

- Inclusion in PubMed, CAS, Scopus and Google Scholar

- Research which is freely available for redistribution 